\title{
How Financial Enterprises Deal with Crisis Public Relation
}

\author{
Hongxin Li \& Chunfeng Yang \\ School of Economics and Management, Changchun University of Science and Technology \\ Changchun 130022, China \\ E-mail: 609677303@qq.com
}

\begin{abstract}
This article firstly introduces implication and basic functions of financial enterprises, theories of crisis public relation and necessity of financial enterprises in management of crisis public relation. Major problems of management of crisis public relation in financial enterprises include, imperfectness of internal system of financial enterprises, deficiency of crisis prevention system, weakness of the consciousness of crisis precaution, lack of experience in crisis public relation and deficiency of conclusion of post-assessment of crisis. Resolution of problems existing in management of crisis in financial enterprises can be conducted from the three aspects of precaution prior to the crisis, including improving financial system, setting up crisis early warning system and offering cordial service, disposal after occurrence of the crisis, including rapid response, sincere communication, public disclosure of the truth, focus on public opinions and asking the government for help, and rehabilitation after the crisis.
\end{abstract}

Keywords: Financial enterprises, Crisis, Crisis public relation, Management of crisis public relation

It is a research subject that has to be encountered to strengthen crisis management of financial enterprises, employ crisis public relation in management of financial enterprises and study basic patterns of financial enterprises to prevent and deal with a crisis, which has great realistic significance to stable development of financial enterprises.

\section{Implication and basic functions of financial enterprises}

Financial enterprise, also termed as financial intermediary organ, is the medium of capital flow in the entire financial system. It is a kind of enterprises that regards providing customers with financial products and financial service as the primary business, mainly including banks and other deposit and savings institutions, insurance company and investment company, etc.

There are various patterns of financial enterprises, with different functions. However, as a medium that effectively circulates necessary funds to prevent flow from surplus unit to deficit unit and realizes transfer of resources, banks are the most typical. Banks mainly have the following important functions: credit medium for circulating capital, effectively transferring social resources, creating credit monetary and expanding credit, providing wide financial service, etc.

\section{Crisis public relation theories and necessity of management of crisis public relation in financial enterprises}

\subsection{Crisis}

Crisis means an emergency that enterprises suffer from serious loss or are faced up with serious loss and threat. This kind of emergency can spread to a wide social scope within a quite short period of time and exerts baneful influences upon enterprises or their brands.

Characteristics of an emergency can be summarized as follows: (1) abruptness, (2) difficulty in predictability, (3) serious harmfulness, and (4) attention of public opinions. We can find out that an emergency has an obvious double-edged feature from the characteristics of a crisis.

\subsection{Crisis public relation}

The so-called crisis public relation refers to a general term of a series of public relation activities in which a social organization prevents and supervises a potential crisis and effectively controls and deals with a crisis that has already broken out to recover or maintain a good public relation condition. The basic purpose of crisis public relation is to ensure that the good public relation between the social organization and the public is not or hardly affected, so as to guarantee survival and development environment of the social organization and reduce the 
negative influences of the crisis to its minimum degree.

A good public relation can enable a social organization to be able to keep good relation with the public even before a crisis event, so as to maintain normal operation of the social organization, protect its public image and reduce the negative effects of the crisis to its minimum degree. Furthermore, a crisis public relation can turn the crisis to a favorable opportunity. Each crisis itself contains root causes for failure and, at the same time, also breeds seeds for success. It is the quintessence for management of a crisis to discover, cultivate and harvest this potential opportunity for success.

The "5S principles of crisis public relation" put forward by Mr. You Changqiao, President of KeyPoint Communication Group, is a set of working principle that is quite instructional in practical work of crisis public relation. It specifically includes "Principle of Shouldering the matter, Principle of Sincerity, Principle of Speed, Principle of System and Principle of Standard".

\subsection{Necessity of management of crisis public relation in financial enterprises}

As a kind of corporate institutions which offer financial products and services, financial crisis have similar functions with common enterprises. At the time of dealing with basic business, financial enterprises should also take into consideration all sorts of details in management and service. In face of all varieties of crisis, financial crisis ought to have their own response plan to adapt to the fierce competition of the market economy.

From the perspective of maintaining financial security and social order, financial crisis management is a sort of the most typical public products, whereas from the perspective of maintaining financial order, financial crisis management is a sort of public products that the government has to furnish in time. Any crisis can be possibly and directly related with the financial security and financial stability of the country at the time when it endangers the financial enterprises. Thus, demand on public relation in the process of dealing with a crisis accident for financial enterprises is higher.

\section{Major problems existing in management of crisis public relation in financial enterprises}

\subsection{Imperfect system of crisis disposal in financial enterprises}

When faced up with changes of operation environment, financial enterprises have to set up a set of complete crisis disposal system in order to effectively conduct business and disposal problems. However, as a result of weak basic management of financial enterprises and lack of basic data and lagging of research and development of information system in financial enterprises, almost all of them have not set up compete crisis analysis and disposal system.

\subsection{Weakness of the consciousness of crisis precaution}

Almost a large majority of crisis comes from disadvantages or errors in daily operation activities of the financial enterprises, such as, dissatisfaction of customers caused by decision making error of business in financial enterprises, dissatisfaction of customers caused by financial service quality, dissatisfaction of customers caused by imperfect functions of financial products and customers venting on financial enterprises for capital loss of customers themselves. Financial enterprises have seldom made careful analysis and reflection on the crisis environment they are encountered, have no clear and sober idea in skills and methods of crisis management and are seriously lacking in the consciousness of crisis.

\subsection{Lack of experiences in crisis public relation}

From the tense of occurrence of a crisis incident, most crisis incidents need to be processed after the event, which requires the managerial personnel of financial enterprises to have high response capacity and decision making capacity. However, as a matter of fact, a large majority of enterprises are quite disappointing in presence of a crisis. Firstly is their irresolution, as a result of which they lose the optimal opportunity to resolve the problem. Secondly is their avoidance of the media, as a result of which they lose the best opportunity for explanation. Thirdly is that they are absorbed in merely simply the immediate interests and try to pass the buck. Fourthly, some financial enterprises have no unified thinking among their managerial personnel for disposal of a crisis incident, which can not be understood and accepted by customers, and which will necessarily make the state of affairs more and more serious.

\subsection{Deficiency of conclusion of assessment after the crisis}

Competence of crisis public relation is also the reflection of core competitive force of an enterprise and conclusion of assessment on occurrence and disposal of a crisis is the best opportunity to check and revise management and operation system of the enterprise. Fundamentally speaking, a financial enterprise has to set up and improve all sorts of systems in order to prevent occurrence of a crisis. Each crisis itself not only contains 
root causes for failure, but also breeds seeds for success. It is the quintessence of crisis public relation to discover, cultivate and harvest this potential opportunity for success. After they pull through a crisis successfully, they are indulged in joy and make light of summarizing and assessing the entire process of dealing with the crisis and even forget. Assessment and summarization after the crisis helps to improve the financial institutions and crisis disposal mechanism.

\section{Methods of financial enterprises to manage crisis public relation}

In order to resolve issues in management of crisis public relation in financial enterprises, we put forward the following resolution methods.

\subsection{Measures of precaution prior to the crisis}

It is the incubation period of crisis prior to the crisis. Competition aggravates the possibility of occurrence of the crisis. Precaution of the crisis can enable financial enterprises to be fully prepared when the crisis occurs and this is the guarantee for successful disposal of the crisis.

\subsubsection{To accelerate reform and improve the financial system}

In order to control and prevent financial risks, financial institutional reform needs to be continuously carried out since financial institutional reform has quite significant effects on improvement of financial system. Perfect financial system is helpful to effectively prevent financial risks. Financial risk is the prelude of a financial crisis, and if the financial enterprises do not eradicate a financial risk in its infancy, then there will be no end of trouble in the future. In order to ensure effective precaution of a financial risk, financial enterprises need to make efforts in macro, medium and micro aspects. In terms of macro aspect, financial enterprises should take an initiative to strengthen the all-round financial supervision of the government; in terms of medium aspect, financial enterprises should strengthen management of all sorts of financial intermediate organizations at all levels on moral aspect of industrial members. It is indicated by international experiences, effects of self-discipline management by financial intermediate organization in a certain period is obvious; in terms of micro aspect, each financial enterprise is required to continuously improve the corporate governance structure of the company and strengthen internal control system construction through reform and innovation.

\subsubsection{Establishment of crisis early warning system}

Establishment of crisis early warning system in financial enterprises is the most important aspect in crisis management of financial enterprises. It means that financial enterprises take measures prior to a crisis to prevent a crisis from breaking out, and it has the most obvious effect in crisis management. Thus, it is necessary to set up a set of standard and overall crisis precaution system. This mainly includes: to conduct well all crisis management work meticulously and carefully within an internal crisis management group in an enterprise; to strengthen the crisis consciousness of all staff; to discover any omen of a crisis in time; to conduct simulation training for crisis management; to establish good relationship with the government and the media, etc.

\subsubsection{Cordial service to reduce service crisis}

Through all surveys, it is discovered, quite a large amount of service crisis underlies in financial enterprises. Competition environment requires an obvious improvement in terms of service in financial enterprises so as to reinforce competitive force of the enterprises and reduce probability of a service crisis. The slogan of "family-based service" proposed by financial enterprises is a necessary means for enterprises to gain victory in competition. The so-called "family-based service" means that, a service should be based on "human relationship", should regard customers as a close relative, should stand in the position of customers to consider a problem, should be worried about what customers are worried about, should think about what customers think about, should start out from the immediate interests of customers, should regard customers as friends and relatives and should enable customers to have the felling of "home" when they go to the service counter. Financial enterprises should play their subjective initiative in terms of service means and conduct family-based service at different time and places for different people and reasons. Then, they can gain trust of more customers, improve the operation efficiency and image of a brand of the enterprises and keep an invincible position in a fierce competition.

\subsection{Methods of disposal of a crisis}

Crisis public relation is an important measure for crisis management and has significant effect on governance of a crisis. Its major task is to let all circles of the whole society know about facts and truth, guide correct public opinion orientation, gain their understanding and support and gain time for crisis management. We put forward the following several points to do appropriate crisis public relation work after occurrence of a crisis. 


\subsubsection{Rapid response and control over the situation}

"Extreme period, extreme rule". Considering the characteristics of abruptness of crisis, we have to start crisis management response mechanism at the first time in order to reduce danger to the largest extent, reduce levels of organizational management, accelerate decision making action, enable the public to appreciate attitude and action of enterprises within the shortest period of time, gain understanding of the society and make the crisis resolved successfully. The attitude of response to a crisis usually directly affects diffusion and deterioration of the crisis and determines whether we can grasp the opportunity and even eradicate the crisis in its infancy. If an enterprises asks for instructions of all levels of its management, focuses on all aspects and procedures, then it may lose the confidence of the society and spoil the opportunity to win a battle.

Since financial enterprises have the characteristics of high crisis abruptness, large influential scope and rapid dissemination, when the crisis comes, the speed of response directly relates with effects of handling a crisis incident, so it can be said that crisis public relation is the most critical and first step. When a crisis occurs in financial enterprises, these enterprises should keep a calm mind, face up with the crisis with a positive attitude and make response with the fastest speed to control spread of the crisis and grasp the opportunity.

\subsubsection{Sincere communication and public disclosure of the truth}

We should never ignore the influential power of a sincere attitude of an enterprise towards the pure public. Whatever an enterprise which is always willing to tell the truth does, it is always indicated that this enterprise has the sincerity to take responsibility for its own behavior. When an enterprise is in a crisis whirlpool, it is a focus of the public and the media. Its every act and every move will be suspected. Thus, an enterprise should not have a fluke mind and should not have the intention to muddle through. On the contrary, it should take the initiative to contact with the news media, attempt to communicate with the public as soon as possible, explain the truth of the fact, promote mutual understanding of the two parties and eliminate doubts and worries.

When a crisis occurs, the Principle of 3T (Tell The Truth) is the most popular principle to handle a crisis at present. It is an effective prescription to resolve a crisis to strengthen the communication and management after a crisis. When necessary, an enterprise can communicate with the party involved in the crisis, hold a press conference and resort to the media to clarify some facts to the public and control spread of the crisis.

\subsubsection{Emphasis on public opinions and asking the government for help}

In the entire process of crisis incident, financial enterprises ought to strengthen corporation with news media and local government and eliminate unfavorable influences up the hilt.

The core content of crisis management is information dissemination management. Media are the major channel of crisis dissemination and it is the responsibility and obligation of media to disseminate crisis information to the public. Enterprises should pay attention to friendly cooperation with media and supervise well direction of public opinions. They should not only publicize information in time, but should effectively lead direction of public opinions. They can resort to support of the third party in authority or institution. For example, they can invite famous experts or scholars to make professional judgments, quote standards of international authoritative institutions and get verification of national special institutions, which can usually head off a danger and take turn to be out of danger.

If a financial enterprise takes an open attitude in handling a public relation crisis and makes full use of modern crisis public relation means, it can not only effectively maintain the perfect reputation of the institution in financial market, but is helpful to strengthen the strong confidence of the market and investors in the institution. When a crisis occurs, financial enterprises should take the initiative to cooperate with the media, attach great importance to the media, make full use of the media and pay attention to influences of the market power and social public trust, which is a kind of mentality and which is more a kind of idea.

The government and relative supervision sections are macro regulators of financial enterprises. When a crisis occurs, financial enterprises should not forget power of the direct controller of national economy. Matters of financial enterprises are usually related with stable development of the national economy. Thus, turning to the government for help can make financial enterprises obtain stronger power and more advantageous resources to resolve and control a crisis.

\subsection{Rehabilitation of a crisis}

When the crisis incident passes, we have to make an assessment on the entire process of disposal of the crisis incident, summarize experiences and lessons, accumulate experiences and provide guarantee for the work of disposal of a crisis in the future. After the crisis management comes to an end, the enterprises should finish a 
crisis management summary or report to summarize crisis management experiences and provide text material for improvement of crisis management system. Crisis management summary mainly includes description of the affair, description of the crisis management process, assessment on crisis management effect and opinions to improve crisis management system.

The term "crisis" has the pun implications of "danger" and "opportunity". How to seek for opportunities in a crisis requires the financial enterprises to continuously absorb experiences and lessons in disposal of a crisis incident and learn advanced crisis management theories in foreign countries. In such way, these enterprises can nip a crisis in the bud before the crisis happens and really deal with the crisis public relation and successfully resolves various crises when the crisis happens. Financial enterprises can improve the crisis public relation management by means of carrying out some effective measures.

\section{References}

Kevin Dowd et al. (1999). Current issues in financial and monetary economics. China Tax Publishing House.

Su, Weilun. (2000). Crisis Management --- Manual of Practical Management in Modern Enterprises. China Textile and Apparel Press, Edition 1, August.

Wang, Hongmei \& Wang, Yuzhong. (2006). Brief Analysis of Crisis Management in Financial Enterprises. Finance Theory and Teaching, No. 4.

Zhang, Weigong. (2009). Advantages far outweigh disadvantages in influences of financial crisis on Chinese finance. Seminar on "analysis, predict and prospect of Banking, Securities Industry and Insurance Industry in China in 2009".

Zheng, Yuanyuan. (2008). Credit and Financial Crisis. Popular Business, No. 1.

Zvi Bodie \& R.C.Merton. (2008). Finance. Beijing: China Renmin University Press. 